\title{
Global AICIME - An integrated approach to support SMEs in the global electronic commerce environment
}

\author{
A. D. de Oliveira \\ M. F. de Oliveira \\ ALFAMICRO \\ Alameda da Guia 192 A - Quinta do Rosário \\ 2750 Cascais - Portugal \\ Tel.: 35114866784 Fax: 35114866752 \\ E-Mail:alfamicro@mail.telepac.pt
}

\begin{abstract}
This paper addresses the problems and solutions faced by SMEs in the context of the new business paradigms: globalisation and electronic commerce. Practical experience and advise is provided as a result of a number of projects which allowed the development and refinement of the Global AICIME (Advanced Innovation and Competitiveness in Manufacturing and Engineering) approach as well as its methodologies and tools including the development of products and integration strategies to tackle the SMEs needs on process re-engineering, reorganisation, management of change and integrated manufacturing management IT systems.
\end{abstract}

\section{Keywords}

AICIME, CIME, virtual enterprise, virtual process, globalisation, SME, electronic commerce

\section{INTRODUCTION}

Industrial and commercial organisations can be thought of as systems which are composed of operational processes structured and regulated by a set of functions that can become strategic; they are currently the object of intense environment pressures.

The mass production and rigid organisational hierarchy paradigms of the so called industrial revolution were replaced by quality and production control as the major areas for manufacturing improvement 10-15 years ago. In the late eighties the focus changed to strategy and business objectives. In the middle of the nineties the focus is changing to globalisation issues concerning access, collaboration and new markets. These are new areas of concern for SMEs which are not well equipped to answer these pressures. Never have these forces been so 
diverse: they are disrupting previous balances and call for rapid and coherent responses as shown in Figure 1.

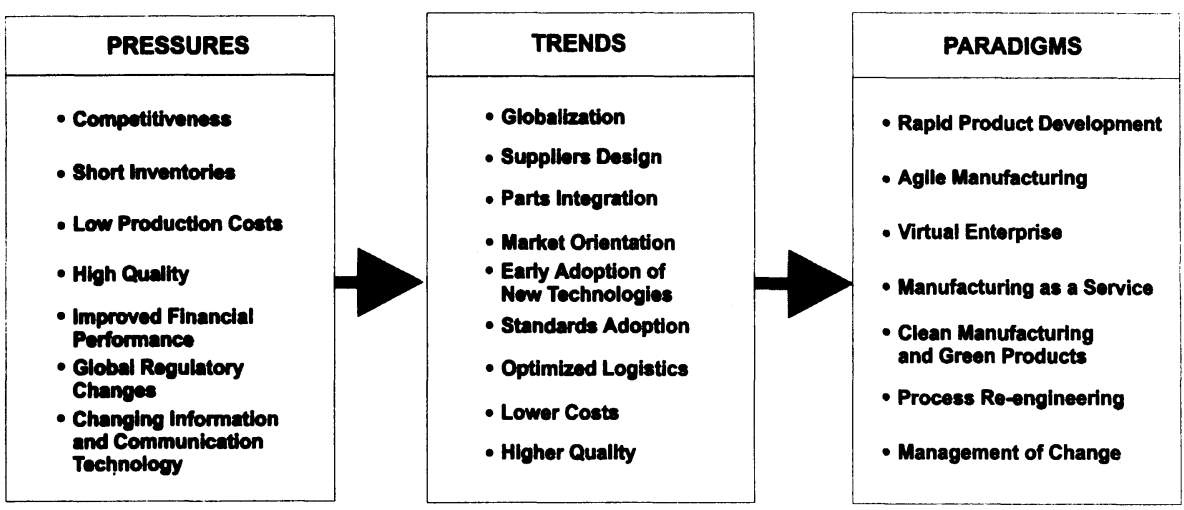

Figure 1 Environmental pressures influencing trends and paradigms.

Major developments are happening in the supply chain management requiring tools and organisation to support the participation of the SMEs. The market globalisation creates new paradigms for the SMEs and multiple responses which imply co-ordination and integration in an approach with a clearly defined strategic character.

Only through the use of clear, simple, flexible and opportune strategy it is possible to overcome the extreme instability that is characterising the business environment.

The ability to use operational information, integrating it quickly, allowing the formulation of plans of action and supporting management decisions at operational and strategic level is critical to sustain the business competitiveness. Global AICIME has developed a methodology and tools which are able to identify the most effective business indicators in a specific organisation and obtain the relevant data models from structured data which is extracted from single or multiple databases.

The Global AICIME MDSS (manufacturing decision support system) integrates data from different sources: shop-floor, production planning and control and business system. This tool enables companies to formulate and achieve their objectives, allowing them to seize and to take advantage of opportunities as they arise, while at the same time, remaining in tune with their environment.

The changing environment of business globalisation is giving way to many new domains of electronic commerce where virtual manufacturing enterprises need to act seamlessly integrated in a network of companies which increasingly tends to be organised as a logistics chain combining effectively the physical flow of materials and goods as well as related information. The logistics chain enables companies to control the flow from downstream to upstream and to optimise, in terms of cost and level of service, the whole physical movement, pulled by demand as shown in Table 1 .

Global AICIME approach is a far-reaching total approach which is both transversal and very ambitious. Its main role is to synchronise the overall physical flow, in permanent interactions with all of the functions of the company and its environment. The responses that companies 
formulate to respond to the global environment pressures imply combined and synergetic responses from complementary expertises and capabilities.

Table 1 Evolution of global logistics activities

\begin{tabular}{|c|c|c|c|c|c|c|}
\hline & \multicolumn{6}{|c|}{ OPERATIONAL PROCESSES } \\
\hline & $\begin{array}{c}\text { Product } \\
\text { Development }\end{array}$ & $\begin{array}{l}\text { Materials and } \\
\text { Parts } \\
\text { Procurement }\end{array}$ & Production & Distribution & $\begin{array}{c}\text { After } \\
\text { Sales } \\
\text { Service }\end{array}$ & Recycling \\
\hline $\begin{array}{c}\text { Distribution } \\
\text { Logistics }\end{array}$ & & & & $\boldsymbol{V}$ & $V$ & \\
\hline $\begin{array}{l}\text { Integrated } \\
\text { Logistics }\end{array}$ & & $V$ & $V$ & $V$ & $V$ & \\
\hline $\begin{array}{c}\text { Integrated } \\
\text { Logistics } \\
\text { Support }\end{array}$ & $\checkmark$ & $\checkmark$ & $\checkmark$ & $\checkmark$ & $\checkmark$ & \\
\hline $\begin{array}{c}\text { Global } \\
\text { Logistics }\end{array}$ & $\checkmark$ & $\checkmark$ & $\checkmark$ & $V$ & $V$ & $V$ \\
\hline
\end{tabular}

The required access and sharing of knowledge and information imposes new models for the organisation and IT tools to support them. The management of the simultaneous competition /co-operation paradigms is a critical factor in the SMEs networking at product development, materials procurement manufacturing, warehousing, distribution, after-sales service and the recycling processes.

The Global AICIME approach encompasses: strategy, methodologies and tools, which have been developed, tested and consolidated in a large number of projects addressing the needs of the Portuguese, Greek, German and Italian companies. Global AICIME has developed and acquired experience in the following domains:

- Effective knowledge transfer.

- Technology transfer between European regions.

- Virtual team work with experts from different European countries.

- Virtual software development at remote locations.

- Integration of different products.

- Distributed design and manufacturing.

- Virtual product development.

- Advanced integrated logistics.

- Personal mobility: cultural knowledge and adaptability.

The functional architecture of a company must continually adapt to the existing trends originated by external and internal pressures, as new trends are originated and new business paradigms are created as a response. These paradigms although broadly recognised by the industry are slower to be adopted by the SMEs due to the difficulty of providing reference criteria and evaluation methods necessary to achieve "tangible" evidence of their advantages.

The market needs are today the driving force of the industry requiring fast responses and leading to the emergence of new trends. In the immediate future a new trend is emerging and 
gaining acceptance as different technologies converge to provide a novel global market in the format of the global electronic commerce. The Global AICIME approach intends to provide answers for the changes faced by the SMEs in this new environment.

\section{AICIME APPROACH}

ALFAMICRO in co-operation with other European partners has conceptualised, developed and applied a well defined model represented in Figure 2, that enables industrial companies to embrace the new business paradigms minimising the existing barriers in their adoption, but fully benefiting from their advantages.

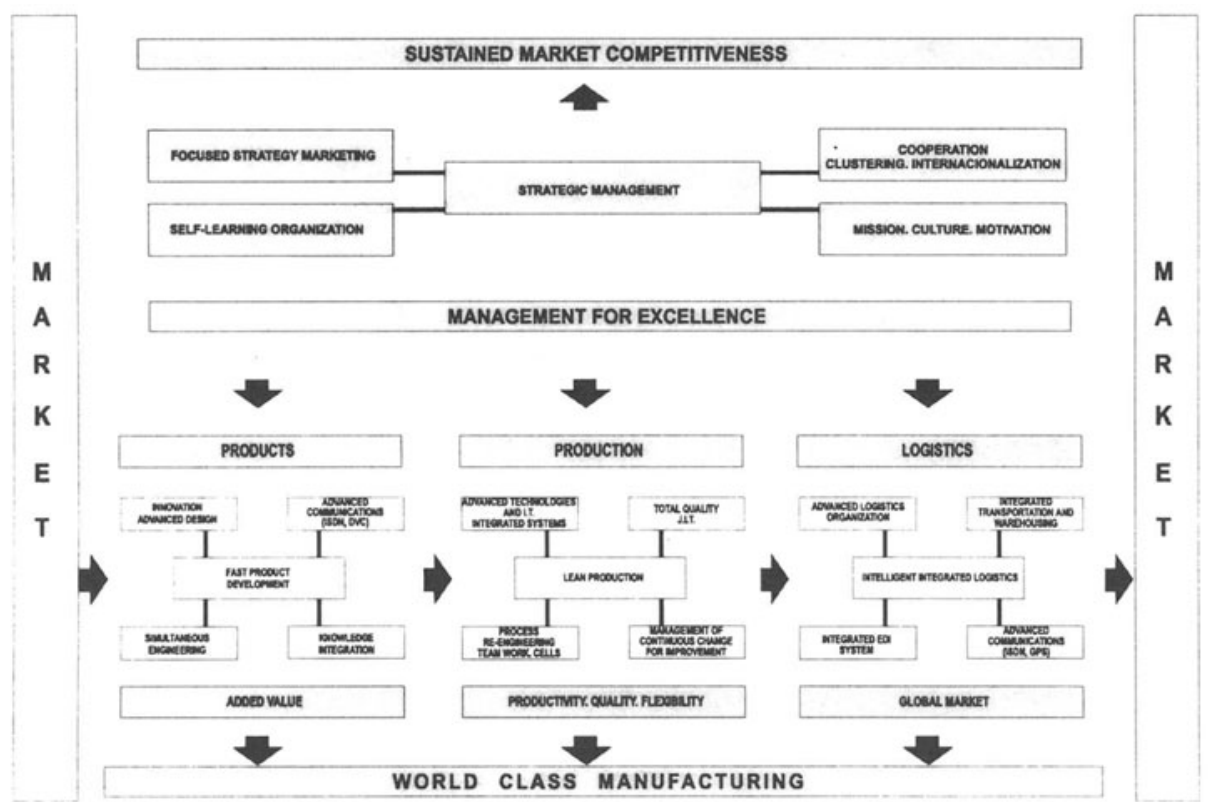

Figure 2 AICIME intervention model.

The organisational and technological approach evolves from a comprehensive understanding of the business strategy and processes leading to the design and application of their reengineering through the management of organisational changes, process optimisation and sustained self learning processes supported by a dynamic approach to innovation. This methodology is supported by different tools and IT products which support the design of the AICIME solutions built around the functional IT model shown in Figure 3.

One of the major advantages of AICIME approach is the integration of already existing information islands in a company. This is a strategy which can have a major impact in many other SMEs which hesitate to progress for more sophisticated access to the advantages of information technology due to the barriers created by isolated PC based systems which are not synchronised and many times do not follow a common data structure. 


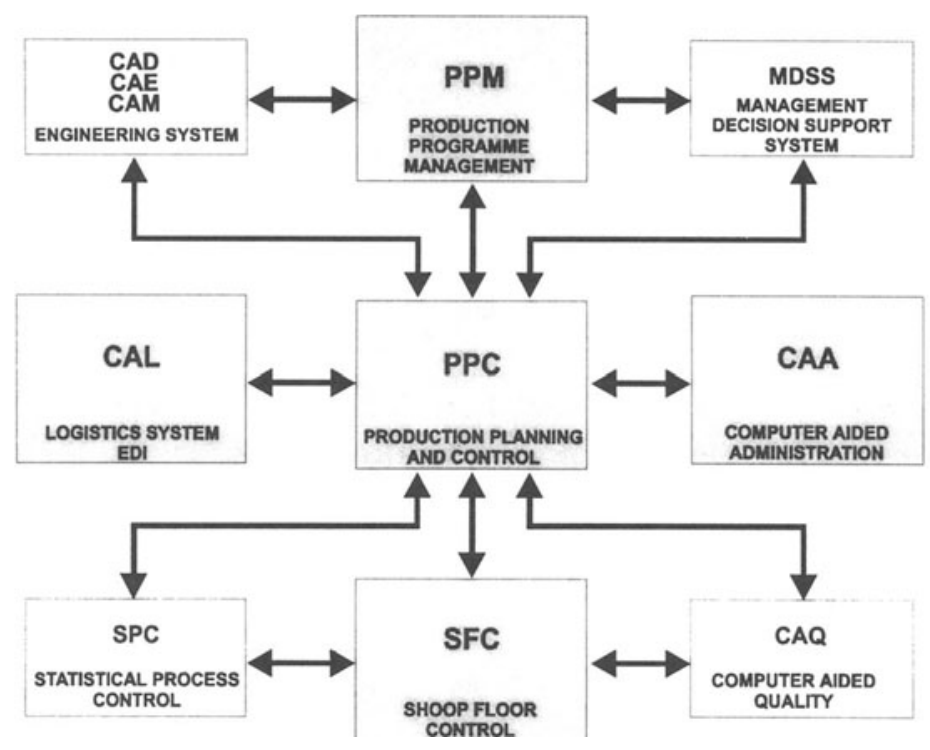

Figure 3 AICIME functional IT model.

\section{GLOBAL AICIME APPROACH}

The AICIME approach presented in the previous section is the result of a dynamic process which is evolving continuously, receiving direct feedback from the experience gained in several applied demonstrator companies. The business globalisation and the electronic commerce environments led to an evolution of the strategies, methodologies and tools which are presented in the Global AICIME IT model shown in Figure 4. Global AICIME architecture comprises three main levels:

- Strategic.

- Tactical .

- Operational.

The SFC system at the operational level controls the production on the shop floor and collects the necessary data to manage local decisions and supply the PPC level the MSmaintenance and CAQ-quality systems. They include preventive and corrective maintenance, SPC and quality.

The tactical level includes the PPC, the CAPD ad the IBS: 
- The CAPD is the integration of advanced IT to support virtual processes bringing forth a more productive approach to product design (ISDN videoconference).

- The IBS is the integration of the logistic system with the business system.

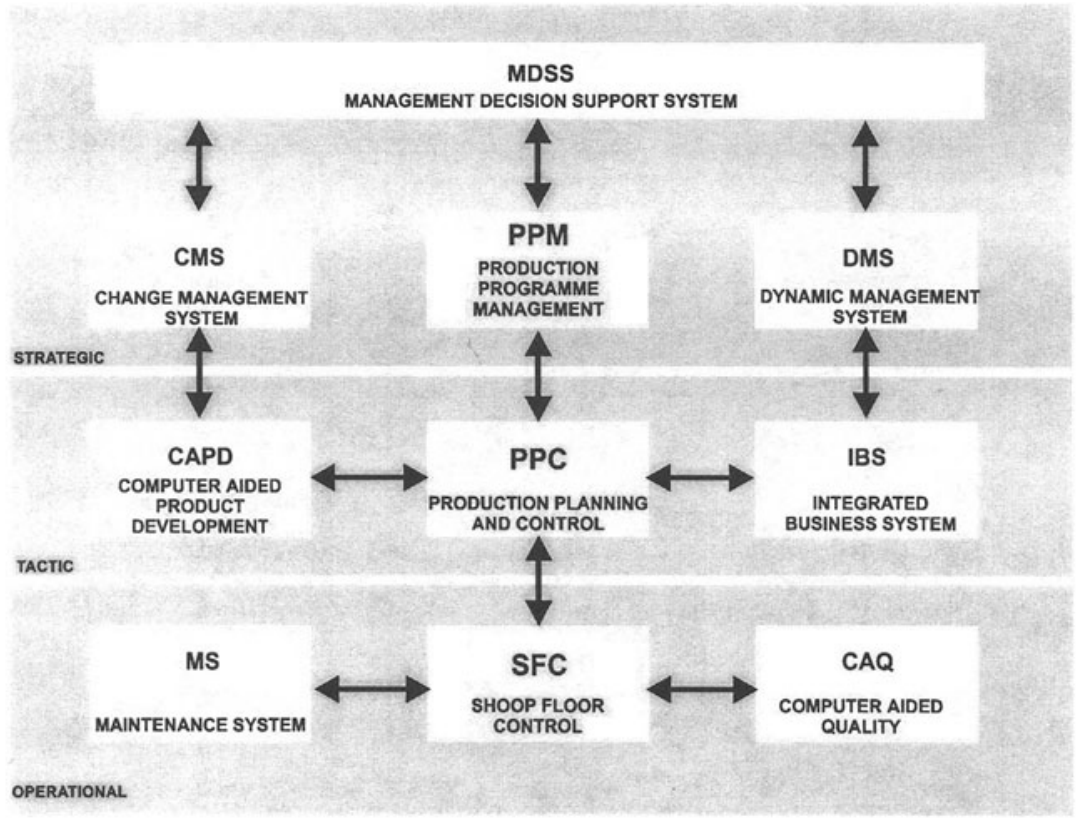

Figure 4 Global AICIME IT model.

The PPC receives and sends data allowing to plan and control all the manufacturing processes. The innovative aspects of Global AICIME towards the AICIME approach is most evident at the strategic level where the MDSS supports the management decisions. The MDSS processes the knowledge relative to the entire productive process, receiving data from the PPC through the PPM. This knowledge is completed with the input from the process simulation and forecasting tools CMS and DMS:

- The CMS handles the management of changes providing a dynamic modelling tool for new processes and optimisation of existing ones. The same system provides local and remote learning to support the skills required by the new organisation.

- The DMS takes in consideration historical and present data together with seasonal and environment trends to build a reliable forecast tool which supports the management of an extended enterprise in the global market. 


\section{GLOBAL AICIME EXPERIENCE}

The extensive experience of ALFAMICRO contributing to the overall Global AICIME architecture is the result of a coherent and determined strategy aiming at gaining the relevant experience of different domains through the practical implementation of a variety of projects as shown in Table 2.

Table 2 Global AICIME Projects

\begin{tabular}{|c|c|c|c|c|c|c|}
\hline & $\begin{array}{c}\text { Product } \\
\text { Development }\end{array}$ & $\begin{array}{c}\text { Materials and } \\
\text { Parts } \\
\text { Procurement }\end{array}$ & Production & Distribution & $\begin{array}{c}\text { After } \\
\text { Sales } \\
\text { Service }\end{array}$ & Recycling \\
\hline \multicolumn{7}{|l|}{ AICIME I \& II } \\
\hline \multicolumn{7}{|l|}{ LOGSME } \\
\hline MDSS & $\checkmark$ & $\checkmark$ & $\checkmark$ & $V$ & $\checkmark$ & $\checkmark$ \\
\hline \multicolumn{7}{|l|}{ PCNET } \\
\hline \multicolumn{7}{|l|}{ ATHENA } \\
\hline \multicolumn{7}{|l|}{ ICIMS-NOE } \\
\hline IiM-B & $\sqrt{ }$ & $\sqrt{ }$ & $\checkmark$ & $V$ & $\sqrt{ }$ & $\nabla$ \\
\hline
\end{tabular}

The fact that most of these projects were or are being developed in LFR demonstrates that it is feasible to provide SMEs localised in these regions with the right tools and approaches to achieve a fast and efficient cohesion with the more advanced environments. The elimination of the competitiveness gap imposes technical, organisational and cultural changes which need to be addressed in an integrated way by a multi-skilled team of experts probably assembled and managed as a virtual team originated from different sources and gathered to achieve a common objective in a specific project. This is one of the main strengths gained by the virtual team managed by ALFAMICRO. This experience has been acquired in Portugal and also applied elsewhere in other regions of the European Union. The Global AICIME approach is characterised by:

- Market focus

- Market globalisation

- Electronic commerce

- Virtual enterprising

- Process re-engineering. Management of changes

- Advanced technologies

- Low cost solution

- Pro-active dissemination of results

- Use of reference models: demonstration and benchmarking

- Effective management of changes

- Multi-disciplinary teams operating as a virtual enterprise

- Reusable experience strategy

This approach has been completed with the implementation of a number of products which support all the major processes of the extended enterprise. ALFAMICRO has gained 
experience in developing, implementing and integrating these products. Summarised in Table 3 is the range of products which are part of this experience and knowledge.

Table 3 Global AICIME Products

\begin{tabular}{|c|c|c|c|c|c|c||}
\hline $\begin{array}{c}\text { Global } \\
\text { AICIME } \\
\text { Products }\end{array}$ & $\begin{array}{c}\text { Product } \\
\text { Development }\end{array}$ & $\begin{array}{c}\text { Materials and } \\
\text { Parts } \\
\text { Procurement }\end{array}$ & Production & Distribution & $\begin{array}{c}\text { After } \\
\text { Sales } \\
\text { Service }\end{array}$ & Recycling \\
\hline PCNET & $\checkmark$ & & & & & \\
\hline PPC pro & & & $\checkmark$ & & & \\
\hline TRITON & $\checkmark$ & $\checkmark$ & $\checkmark$ & $\checkmark$ & $\checkmark$ & $\checkmark$ \\
\hline PROFIT & $\checkmark$ & & $\checkmark$ & & & \\
\hline $\begin{array}{c}\text { LOG } \\
\text { FORECAST }\end{array}$ & $\checkmark$ & $\checkmark$ & $\checkmark$ & $\checkmark$ & $\checkmark$ & $\checkmark$ \\
\hline $\begin{array}{c}\text { EDI } \\
\text { MANAGER }\end{array}$ & & $\checkmark$ & & $\checkmark$ & & \\
\hline $\begin{array}{c}\text { MDSS/DMS } \\
\text { /CMS }\end{array}$ & $\checkmark$ & $\checkmark$ & $\checkmark$ & $\checkmark$ & $\checkmark$ & $\checkmark$ \\
\hline
\end{tabular}

\section{FUTURE WORK. CONCLUSIONS}

The continuous and dynamic changes characterising the market globalisation and the ever increasing competitive pressures are taken by ALFAMICRO as a challenge to be fully explored, to the advantage of the SMEs. The benefits of the modern communications such as ISDN and Internet and multimedia applications are the strategic low cost tools to achieve sustained competitiveness.

These tools allow simple technical business networking where individual competencies and skills can be brought together as a virtual enterprise linked at different bonding levels.

The experience of AICIME demonstrates that it is possible to achieve advanced levels of consultancy, engineering and supporting information technology using virtual teams with the appropriate profile.

The successful AICIME strategy provides solutions for the SMEs problems, taking in consideration their present resources and culture.

The evolution for virtual enterprising in the proposed GLOBAL AICIME approach allows the SMEs to handle to their advantage the new paradigms of market globalisation and electronic commerce including the far reaching capabilities of virtual work environments for product development and dynamic management decision support tools. 